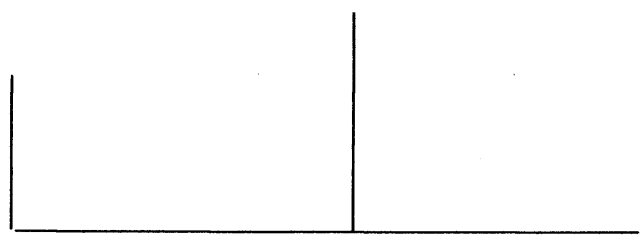

Rev. Latinoam. Psicopat. Fund., VIII, 2, 346-355

\title{
Estabilidade estrutural e psiquiatria
}

Fernando Portela Câmara, MD, PhD

\begin{abstract}
Nonscientists tend to think that science works by deduction. But actually science works mainly by metaphor. And what's happening is that the kinds of metaphor people have in mind are changing... Instead of relying on the Newtonian metaphor

of clockwork predictability, complexity seems to be based on metaphors more closely akin to the growth of a plant from a tiny seed, or the unfolding of a computer program from a few lines of code, or perhaps even the organic, self-organized flocking of simpleminded birds.

(Waldrop, p. 327 and 329; see also p. 149)
\end{abstract}

O ideal de uma classificação psiquiátrica é estabelecer uma linguagem comum a quaisquer psiquiatras em qualquer parte do mundo, por meio da qual possam se comunicar de forma uniforme e inequívoca, descrevendo os fenômenos psiquiátricos sem o viés das diferentes culturas. Para tal, usam-se instrumentos de pesquisa validados para uso internacional, e análise estatística rigorosa. Com isto, a epidemiologia e a distribuição dos transtornos mentais podem ser conhecidas de forma confiável em qualquer parte do planeta, 


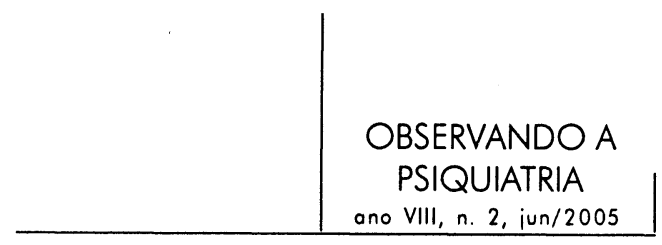

ajudando, entre outras coisas, a implementação de políticas de saúde mental com base em dados seguros.

Entretanto, uma classificação deve ser mais do que isto: ela deve refletir a estrutura da ciência de que participa e prover uma explicação simples e razoável para a origem dos seus conceitos. Em outras palavras, ela deve ser não apenas taxonômica, mas morfogênica, orgànizando-se segundo a direção em que os processos mentais se diferenciam e ocasionalmente sofrem rupturas que se convencionou chamar "transtornos mentais".

A grande crítica às classificações atuais (CID-10 e DSM-IV), além da suposta desimportância dada à exploração psicopatológica, está na dificuldade de distinguir efeito da cultura e do millieu na patoplastia dos transtornos mentais. Chakraborty (1991), recorda como as influências das culturas européia e norte-americana nas classificações mencionadas, respectivamente CID e DSM, resultaram em numerosos vieses culturais e cripto-racismo, seqüelas do racismo científico e mentalidade colonialista do ainda existente eurocentrismo. Uma consequêencia disto é a frequiente crítica feita a estas classificações de tratar tudo o que é cultural como não-europeu e o que é europeu-(norte)americano como social (Chakraborty, 1991; Sashidharan, 1986).

A variável cultura na psiquiatria é freqüentemente um viés que encobre e obscurece fatores econômicos, políticos, sociais, biológicos e ambientais (Jablensky, 1975; Wallace, 1975; Dick, 1995). Deste modo, a interferência deste viés nas classificações psiquiátricas tende a distanciar a psiquiatria do seu real objeto. Os dados etnográficos sugerem fortemente que, excetuando os transtornos psiquiátricos de natureza orgânica, somente cinco síndromes psiquiátricas de adultos são encontradas em todas as culturas: as esquizofrenias, as psicoses reativas breves, a depressão unipolar, o transtorno bipolar e os transtornos de ansiedade, que vão dos estados de pânico às fobias, ao transtorno obsessivocompulsivo (Kleinman, 2000). Portanto, muito do que é tido como "cultural" pode ser reinscrito dentro destas categorias quando estudado mais profundamente.

Muitos dos transtornos descritos no DSM-IV são culturalmente ligados à euro-américa (ibid.). Um exemplo conhecido deste viés é a distimia, cujo diagnóstico encontra coerência no mundo ocidental desenvolvido, e que se torna freqüentemente uma medicalização de problemas sociais nos países com graves problemas econômicos, onde prevalecem sentimentos endêmicos de desesperança e desamparo, desespero e humilhação (Kleinman, 1987). Igualmente, para alguns autores, transtornos tais como a anorexia nervosa e a síndrome da fadiga crônica deveriam ser considerados síndromes relacionadas à cultura, já que foram fortemente delineados dentro da cultura norte-americana (Lopez e Guernaccia, 2000). Estas questões nos obrigam a pensar que os métodos classificatórios atuais 


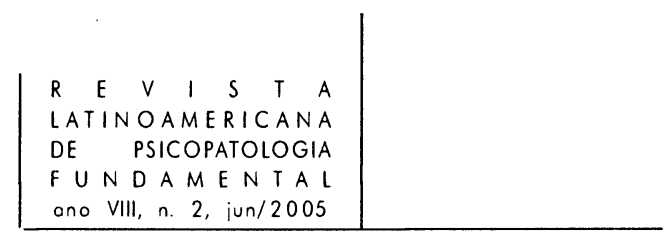

estariam produzindo artefatos e importando-os para a psiquiatria, trazendo confusão à delimitação do seu campo conceitual.

Aparentemente, os métodos de classificação ainda não são suficientemente rigorosos e conclusivos para identificar uma estrutura inerente à psiquiatria, portanto, autorizando seu estatuto científico. De fato, uma classificação deve refletir a estrutura conceitual de uma ciência, e devemos entender tal estrutura como sendo uma ocorrência real de entidades que existem estavelmente e que, por tal, são reconhecidas e nomeadas. O que importa, portanto, é discutir o caráter estrutural da psiquiatria e como ele deve orientar as linhas de força que devem moldar toda e qualquer classificação segundo essa estrutura.

Em psiquiatria, critérios objetivos como marcadores bioquímicos, histoquímicos, cromossômicos, produtos de expressão gênica, antígenos etc., não são a via de regra para a classificação de doenças, como acontece nas outras especialidades médicas. De fato, em muitos casos, parte das propriedades utilizadas são eminentemente subjetivas, porém supõe-se existirem como vivências humanas que se aglomeram de forma suficientemente estável e duradoura (um cluster) para que sejam notadas e caracterizadas como algo "anormal", e que devem ser suficientemente distintas da cultura local. Por exemplo, um indivíduo que está há mais de duas semanas com humor deprimido, ruminando sentimentos de culpa injustificados, de desvalia, com idéias suicidas, despertares precoces, perda significativa de peso etc., sem que haja uma causa aparente para o seu estado, manifesta um cluster (isto é, um aglomerado estável de sintomas observado independentemente em muitas pessoas ao mesmo tempo e ao longo do tempo) convencionalmente nomeado depressão maior.

Basicamente, o que discuto aqui é que, enquanto a psiquiatria como atividade clínica repousa na habilidade do diagnóstico, este deve refletir a psiquiatria como uma teoria clínica situada no real. A questão será, portanto, estabelecer uma teoria da realidade clínica da psiquiatria e, a meu ver, esta teoria relaciona-se ao conceito topológico dinâmico de estabilidade estrutural.

René Thom (1972) chamou de estabilidade estrutural a propriedade de um sistema manifestar propriedades por um tempo suficiente para ser nomeado, não tendo liberdade para assumir qualquer outra característica possível. Este princípio, embora relacionado às estruturas, sejam elas formas sensíveis, transientes, conceitos ou semânticas, também se aplica às classificações científicas, que passam a ser "orgânicas" na medida em que são descritas num modelo morfogenético em que as formas não decorrem de convenção ou ato criador, mas de um princípio universal. Este princípio pode assim ser enunciado: um processo $P$ é estruturalmente estável se uma pequena variação nas condições iniciais conduz a um processo $P^{\prime}$ isomorfo com $P$, no sentido em que uma pequena transformação no espaço-tempo retorna o processo $P$ ' ao processo $P$ (isto é o 


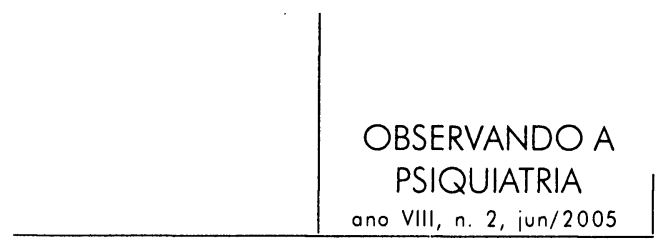

que em topologia conhecemos como um $\varepsilon$-homeomorfismo). Dentro deste princípio, uma condição caracterizada como uma doença mental X deve apresentar estabilidade estrutural para receber este estatuto, ou seja, seja qual for sua manifestação, isto não nos impede de notar sua característica essencial e nomeála corretamente. Dito de outra forma, nem todas as depressões maiores seguem exatamente o mesmo inventário de sintomas (qualquer condição P'), o que não nos impede de reconhecer a convergência do diagnóstico para uma categoria definida (a condição P), portanto, tais variações são apenas homeomorfismos que não afetam a classificação. Em psiquiatria, um processo estruturalmente estável não pode ser culturalmente determinado ou socialmente condicionado, mas uma propriedade que tenha seu centro organizador no próprio indivíduo.

O princípio da estabilidade estrutural é uma teoria geral da origem e natureza da forma, em qualquer sentido, seja ontogênico ou filogenético, fundamenta-se nas leis da dinâmica e, embora explique satisfatoriamente o determinismo clássico, avança neste conceito mostrando que sistemas que se tornam estruturalmente instáveis não podem ser considerados determinísticos, só sendo acessíveis a uma descrição probabilística (ou uma classificação estatística). A moderna "dinâmica não-linear", "dinâmica complexa" ou "teoria do caos", teve neste princípio uma de suas origens. Além disso, a teoria da estabilidade estrutural é uma topologia da dinâmica, enfatizando seu caráter qualitativo e servindo de modelo geral para o determinismo das formas, bem como para as mudanças imprevisíveis que estas podem experimentar quando o seu determinismo é ameaçado por flutuações instáveis.

Todo processo, seja qual for sua natureza, que tende a se organizar em alguma forma, seja esta um olho de vertebrado ou um conceito filosófico, tem uma dinâmica intrínseca representada por uma convergência de todas as suas partes para uma região singular de estabilidade local denominada atrator. Um atrator deve ser imaginado como um potencial mínimo local para o qual evolui ou converge assintoticamente um processo que doravante passará a exibir um comportamento estável.' Qualquer afastamento da condição estável na vizinhança do atrator fará o sistema retornar ao mesmo (como que "atraído"), caracterizando sua estabilidade estrutural (esta região ou vizinhança é chamada de bacia do atrator). As doenças mentais, como qualquer sistema físico, químico, biológico ou

1. Este conceito é originariamente de Laplace, que associou estabilidade a um potencial mínimo de energia, formulando o determinismo científico. Claro que em processos tais como diferenciação celular, embriogênese, estabilidade de ecossistemas, estabilização de economias, bem-estar social etc., este conceito de potencial mínimo não tem sentido físico, porém permanece válido como elemento conceitual para qualquer modelo envolvendo dinâmicas. 


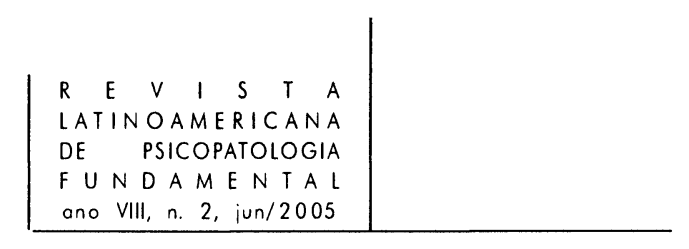

lingüístico, se existem, o fazem porque são governadas por atratores, isto é, elas se formam por um processo dinâmico que lhes dá suficiente estabilidade para existirem, ou seja, serem reconhecidas como uma forma singular, ou receberem um nome. O conjunto destas doenças ou seus atratores formam um meta-sistema, que é uma estrutura conceitual ou uma classificação natural, e devem satisfazer a teoria de realidade clínica da especialidade médica que trata deste conjunto.

Os processos governados por atratores assemelham-se aos processos de formação de um órgão ou tecido num embrião; de fato, estes seguem aqueles. O geneticista e embriologista C. H. Waddington (1940) percebeu ser a diferenciação da célula ovo num embrião uma dinâmica controlada por fluxos e não por um determinismo genético (os genes apenas produzem os ingredientes, sendo a dinâmica complexa dos fluxos que leva às formas, sem necessidade de algum programa previamente existente). Waddington chamou creodos as vias preferenciais seguidas pelos processos embriogênicos para formar um órgão ou tecido específico. Com isso explicava o determinismo embriogênico como uma dinâmica governada por um princípio de estabilidade, o que hoje reconhecemos como atrator. ${ }^{2}$ Esta semelhança entre dinâmica qualitativa e embriogênese não é apenas casual. René Thom (1972) viu nisto a expressão topológica da dinâmica das transformações, da criação e destruição de ordem, uma visão de Natureza compartilhada entre Anaximandro e Heráclito e a ciência moderna. Ele, assim, modelou topologicamente os princípios da dinâmica, ciência que generaliza as transformações, sejam estas orgânicas, físicas ou químicas, psíquicas ou conceituais, e chamou esta dinâmica de morfogênese. Dentro deste princípio, uma classificação não é senão um esforço em descrever um processo morfogênico, portanto, um modelo que não é menos real que o do desenvolvimento do embrião de uma rã ou da semente de uma amendoeira.

2. Waddington, cujos trabalhos foram um dos pontos de partida para a teoria das catástrofes de René Thom, criou o termo creodo e o introduziu pela primeira vez na literatura para designar uma via preferencial de diferenciação em relação a outras possibilidades (Waddington, 1940). Ele explicava como a dinâmica de fluxos durante a germinação cria o embrião sem participação de genes que apenas determinam os ingredientes envolvidos nos fluxos. Os creodos são, portanto, vias preferenciais destes fluxos, levando à formação de um determinado órgão e não outro, exceto em circunstâncias onde o processo sofria perturbações sérias externas, intensas o suficiente para desestabilizar o processo. O conceito denota, portanto, uma dinâmica que leva a uma estabilidade local. Creodos são o que em dinâmica não linear moderna se denomina atrator. Para concluir esta nota, a idéia de fluxos levando a creodos como modelo epigenético para diferenciação ou organização da forma já havia sido discutido, pela primeira vez, no início do século passado, por D'Arcy Thompson, na sua obra monumental On Growth and Form (1961). 


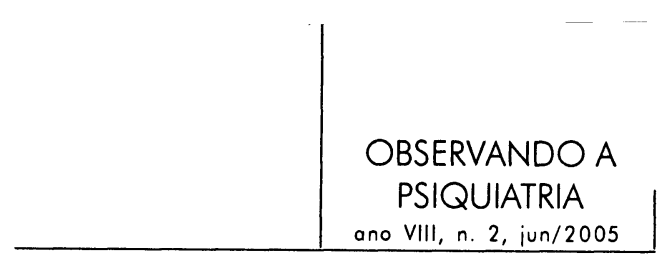

A ocorrência universal de esquizofrenias, psicoses reativas, depressão maior, transtorno bipolar, transtornos de ansiedade e algumas outras condições observadas em todas as culturas e em todos os tempos, evidencia a existência de atratores mentais competindo com as funções psíquicas também governadas por atratores. Os transtornos são considerados "anormais" na medida em que competem com as funções "normais". Ora, do ponto de vista da dinâmica complexa, "morfogênica", atratores se formam espontaneamente quando os parâmetros do sistema atingem certos valores, e formas estáveis podem daí se originar sem que sejam sujeitas a um determinismo genético, ou qualquer programação prévia, mas a um determinismo intrínseco à própria dinâmica ("epigenético"), ou seja, ao processo. Esta perspectiva nos mostra a possibilidade de determinismos unicamente dinâmicos na organização de estados psíquicos, sem necessidade de apelarmos compulsivamente para o deus ex-machina reducionista da explicação genética. $\mathrm{Na}$ falta de conhecimentos precisos e empiricamente demonstráveis sobre o mecanismo das doenças mentais, o modelo baseado na dinâmica qualitativa possibilita-nos insights sobre processos cuja complexidade nossa compreensão atual não consegue acessar. Ora, é esta precisamente a utilidade deste modelo.

Voltando à topologia de René Thom, um processo morfogênico, como, por exemplo, a diferenciação da blástula em gástrula e daí até esboço de um organismo, deve ser visto como uma dinâmica gerando diferentes atratores à medida que experimenta mudanças em seus parâmetros. Isto é comparável a uma paisagem onde ilhas de ordem (atratores) vão se formando (os órgãos), emergindo de um oceano de instabilidade ou indeterminação. ${ }^{3}$ Estas zonas de instabilidades,

3. Waddington chamou este campo em que a natureza se diferencia por efeito de sua dinâmica de fluxos de paisagem epigenética, formando creodos à medida que avança e se torna mais complexa. René Thom redefiniria como campo morfogenético, e a dinâmica não linear moderna de diagrama de bifurcação. Esta paisagem epigenética é uma paisagem de potenciais máximos e mínimos, sendo os máximos regiões de instabilidade ou indeterminação, representadas por picos, e as regiões de mínimos (pensemos sempre em potenciais), representando zonas de estabilidade, como vales. Imagine um bola no alto de um pico: sua posição é instável e ele tende a resvalar; se ela cai num vale profundo, ela tende a ficar lá, portanto, em posição estável. Prigogine modifica esta noção laplaciana usando o termo auto-organização para denotar a dinâmica dos atratores levando à criação de formas. Ele substituiu a noção laplaciana de potencial mínimo pela noção termodinâmica de dissipação de entropia como a forma pela qual tais estruturas mantém sua ordem dissipando sua entropia. Chamou estas estruturas de estruturas dissipativas, e mostrou que elas se formam quando o sistema está afastado do seu equilíbrio, como afinal são todos os processos complexos na natureza. Este conceito é absorvido pelo conceito mais geral de estabilidade estrutural. 


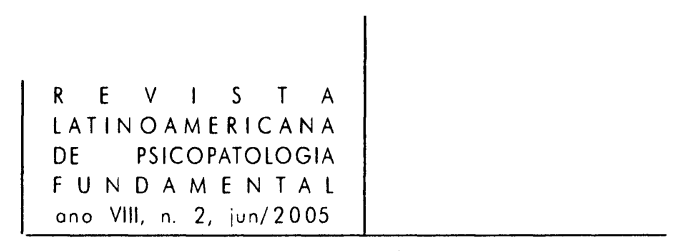

que separam os atratores, representam transições súbitas, descontínuas, de um estado estável para outro, que pode ocorrer em função de uma mudança de parâmetros. Este fenômeno de transição súbita, imprevisível, oriunda de uma instabilidade local, é conhecido em dinâmica como bifurcação, termo criado pelo matemático Henri Poincaré, e que René Thom (1972) renomeou como catástrofe. Um atrator pode ser incorporado por outro ou então se dividir em dois outros com propriedades distintas, e esta dinâmica é universal, sendo a base da dinâmica dos processos naturais, sociais, econômicos, psíquicos e lingüísticos. Deste modo, um processo mental estável pode ocasionalmente, e em certas situações, tornar-se localmente instável e sofrer uma bifurcação, em que mais de um estado (solução, ou atratores) são agora possíveis. A figura 1 ilustra como isto se manifesta analiticamente numa condição mais simples que é a topologia de uma descontinuidade (ou bifurcação, ou catástrofe) emergindo espontaneamente por efeito de uma dinâmica.

Ao mesmo tempo em que identificamos um processo, seja qual for sua natureza, e o situamos no real por evidenciá-lo como estruturalmente estável, estamos paralelamente reproduzindo-o em nossas mentes, pois este processo de cognição não é muito diferente do que ocorre no mundo exterior. De fato, ambos se acoplam. O espaço de nossas mentes pode ser formado por estruturas dinâmicas que simulam as forças organizadoras dos processos naturais, e isto seria precisamente, na concepção de Thom, o objeto do conhecimento. Este modelo de conhecimento é freqüentemente criticado pelos empiricistas como "vãs especulações", apenas por ser qualitativo (Sussman e Zahler, 1976; Zeeman, 1978), ou seja, eminentemente fenomenológico, já que não lança luzes sobre os mecanismos e demais detalhes que levam aos processos observados. Tal crítica, embora válida, não leva em consideração a finalidade do modelo (Saunders, 1980), que é a de proporcionar insights em sistemas cuja complexidade é de tal ordem que seus mecanismos não estão accessíveis à nossa compreensão ordinária, ou ao estágio atual do conhecimento científico. Por outro lado, o conceito de estabilidade estrutural ultrapassa a fenomenologia clássica e não pode ser comparado a ela, dado que a dinâmica qualitativa tem uma capacidade descritiva além dos modelos verbais simples e tem ainda a capacidade de ser preditiva. Além disso, a abordagem fenomenológica nos obriga a concluir apenas em função de nossa percepção, enquanto a dinâmica qualitativa revela uma estrutura matemática preexistente - um modelo ou topologia natural - que abrange o comportamento dinâmico do sistema observado.

Toda especialidade científica trabalha com uma classificação (ou taxonomia) estabelecida a priori, que delimita seu o campo conceitual. Este resulta de uma fragmentação qualitativa do campo perceptual em atratores aparentemente 


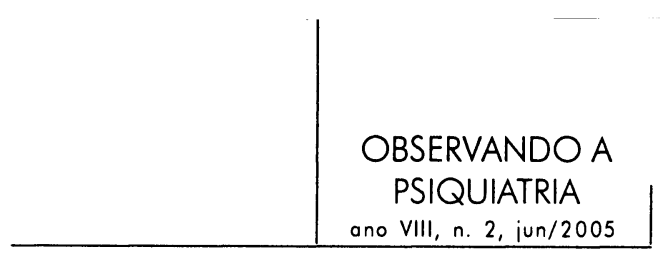

independentes, e será neste campo delimitado pela nossa percepção que os modelos quantitativos, considerados "científicos", serão construídos. Ora, os investigadores raramente se dão conta de que o que consideram como estável e, portanto, reprodutível em seus modelos, nada mais é que uma qualidade do real. Em segundo lugar, não é objetivo da ciência colecionar dados empíricos, mas organizá-los numa estrutura coerente que lhes dê uma finalidade ou sentido, para então termos uma idéia de como as coisas ocorrem. Esta é a definição de modelo, uma ordem criada em nossa mente e cuja dinâmica não é tão diferente do mundo que ela mesma examina e descreve, e por isso dissemos que essas duas dinâmicas se acoplam naturalmente e isto é o que produz o conhecimento. Em psiquiatria, a classificação deve refletir sua realidade, e esta o conhecimento que se organiza pela experiência da realidade da psiquiatria.

Assim como Jourdain fez prosa durante toda sua vida sem o saber, os psiquiatras passam a maior parte do seu tempo classificando sem se darem conta disso. À medida que o discurso do paciente avança, o clínico ouvinte vai repassando quadros clínicos em sua mente até selecionar aqueles que são os mais prováveis para explicar a vivência de seu cliente, ou seja, a vivência estruturalmente estável, o que nomeará o diagnóstico. Ora, ele procura sair de uma região de instabilidade onde vários atratores estão competindo entre si, uma região, portanto, de indeterminação, onde só pode conceber possibilidades (estatisticamente). Procura sair dessa indeterminação buscando uma zona de estabilidade no discurso do seu paciente, até que a complexa dinâmica deste o leva à bacia do atrator que revela a condição estável procurada que lhe dará um nome. Este será o diagnóstico, uma condição inteiramente determinística. Em psicanálise este processo se inverte, mas segue as mesmas leis da dinâmica complexa (ou não-linear); portanto, ela existe no real tanto quanto a psiquiatria, embora o indeterminismo ou a condição de instabilidade estrutural seja aceitável aqui. A psiquiatria tem uma estrutura natural, um modelo dinâmico qualitativo, morfogenético, que traduz sua condição de realidade clínica em uma classificação natural. Enquanto os que propõem uma classificação universalizante não buscarem na natureza do próprio conhecimento e na teoria da realidade clínica sua própria validade, as classificações psiquiátricas serão sempre objeto de controvérsias e inúmeros debates. 


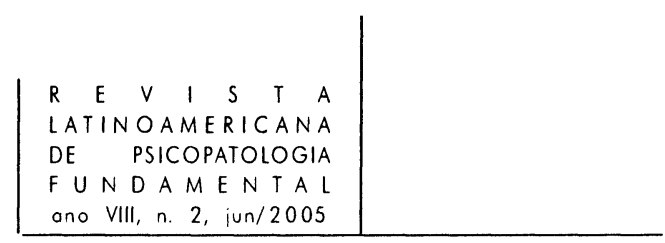

\section{Referências}

Chakraborty, A. Culture, colonialism and psychiatry. The Lancet, v. 337, p. 1204-7, 1991.

Dick, L. "Pibloktoq" (Artic hysteria): A construction of European-Inuit relations? Arctic Anthropology, v. 32, p. 1-42, 1995.

Jablensky, A. e Sartorius, N. Culture and schizophrenia. Psychological Medicine, v. 113, p. 124-9, 1975

Kleinman, A. Anthropology and psychiatry: the role of culture in cross-cultural research on illness. British Journal ofwPsychiatry, n. 151, p. 447-54, 1987.

Social and cultural anthropology: salience for psychiatry. In: GeLDER, M. G., Lopez-IBor, J. J., ANDREASEn, N. C. (orgs.). New Oxford Textbook of Psychiatry. Oxford: Oxford University Press, 2000. p. 300-5.

LOPEZ, S. R. e GuernaCCIA, P. J. Cultural psychopathology: uncovering the social world of mental illness. Annual Review of Psychology, v. 51, p. 571-98, 2000.

Patel, V. e Winston, M. The "universality" of mental disorder revisited: assumptions, artifacts and new directions. British Journal of Psychiatry, v. 165, p. 437-40, 1994.

Prigogine, I. As leis do caos. São Paulo: Ed. Unesp, 2000.

354 Sashidharan, S. P. Ideology and politics in transcultural psychiatry. In: Cox, J. L. (org.). Transcultural Psychiatry. Dover: Croom Helm Ltd, 1986. p. 158-78.

Saunders, P. T. An Introduction to Catastrophe Theory. Cambridge: Cambridge University Press, 1980.

SuSSMAN, H. J. e ZAHLER, R. S. Catastrophe theory as applied to the social and biological sciences: a critique. Synthèse, v. 37, p. 117-216, 1976.

Tном, R. Structural Stability and Morphogenesis: An Outline of a General Theory of Models. Massachusetts: Benjamin Publishing Co., Reading, 1972.

Tномpson, D. On Growth And Form. Cambridge: Cambridge Univ. Press, 1961.

WADDINGTON, C. H. Organizers and Genes. Londres: Allen \& Unwin, 1940.

WALlaCe, A. C. Anthropology and psychiatry. In: FreEMAn, A. M., KAPLAN, H., SAdock, B. J. (orgs.). Comprehensive Textbook of Psychiatry. Baltimore: Williams \& Wilkins; 1975. p. 366-7.

ZeEman, E. C. A dialogue between a mathematician and a biologist. Bioscience Communications, v. 4, p. 225-40, 1978. 

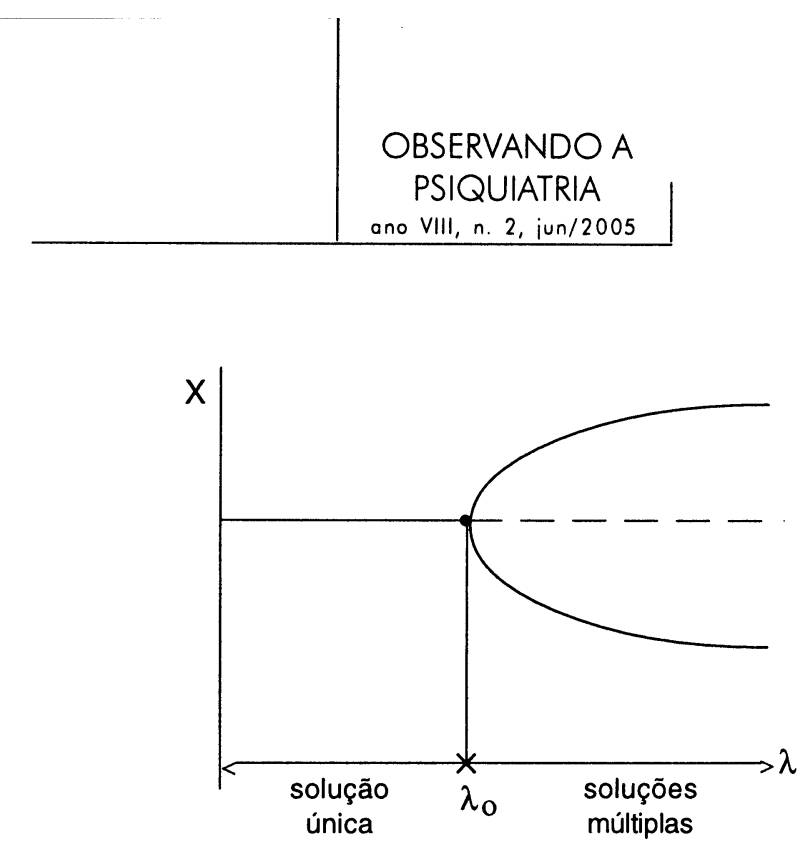

Figura 1 - Bifurcação de uma dinâmica estável, ou seja, de uma única solução (um atrator denominado "ponto-fixo atrator") cujo parâmetro $\lambda$ atinge um valor crítico, $\lambda$ o, onde surge uma instabilidade local que leva o sistema a subitamente se dividir em dois processos ou soluções (dois atratores que se alternam, chamado de "ciclo-limite atrator") que competem entre si. A linha pontilhada ilustra uma fronteira instável cuja aproximação de um dos atratores leva à sua incorporação pelo outro. Esta bifurcação é conhecida como bifurcação de Kopf. Considere que esta dinâmica descreve um estado estável de humor (X) que sob determinadas circunstâncias (drogas, condições associadas ao metabolismo neuronal etc.), pode sofrer uma bifurcação ao atingir uma condição crítica, levando a um estado de euforia alternando-se com depressão. Na condição inversa, estes estados podem se reunir num mesmo atrator por efeito de um estabilizador de humor, uma desintoxicação, a participação de um terapeuta etc. A figura é aqui usada apenas para ilustrar conceitos. 